\title{
Development of adiposity in adolescence: five year longitudinal study of an ethnically and socioeconomically diverse sample of young people in Britain
}

Jane Wardle, Naomi Henning Brodersen, Tim J Cole, Martin J Jarvis, David R Boniface

\begin{abstract}
Objective To examine the developmental trajectory of obesity in adolescence in relation to sex, ethnicity, and socioeconomic status.

Design Five year longitudinal cohort study of a socioeconomically and ethnically diverse sample of school students aged 11-12 years at baseline.

Setting 36 London schools recruited to the study in 1999 by a stratified random sampling procedure.

Participants 5863 students participated in one or more years.

Main outcome measures Weight, height, and waist

circumference measured annually by trained researchers; overweight and obesity defined according to International Obesity Task Force criteria; adiposity and central adiposity indexed by body mass index (BMI) and waist standard deviation scores relative to 1990 British reference values.

Results In school year 7 (age 11-12), the prevalence of overweight and obesity combined was almost $25 \%$, with higher rates in girls (29\%) and students from lower socioeconomic backgrounds (31\%) and the highest rates in black girls (38\%). Prevalence of obesity increased over the five years of the study at the expense of overweight, but no reduction occurred in the proportion of students with BMIs in the healthy range. Waist circumferences were high compared with 1990 norms at age 11 (by $0.79 \mathrm{SD}$ in boys and by $1.15 \mathrm{SD}$ in girls) and increased further over time. Both BMI and waist circumference tracked strongly over the five years.

Conclusions Prevalence of overweight and obesity was high in London school students, with significant socioeconomic and ethnic inequalities. Little evidence was found of new cases of overweight or obesity emerging over adolescence, but few obese or overweight adolescents reduced to a healthy weight. The results indicate that persistent obesity is established before age 11 and highlight the need to target efforts to prevent obesity in the early years.
\end{abstract}

\section{Introduction}

The prevalence of obesity in children and adolescents has almost tripled in Britain in the past 20 years, as it has in the United States. ${ }^{1-3}$ Adolescence has been identified as a critical period for the development of persistent overweight and obesity on the basis of the strong evidence for tracking of adolescent adiposity into adulthood. ${ }^{4-6}$ Adolescent obesity is associated with all the long term risks of adult obesity and may carry additional risks for metabolic disorders and poor body image associated with the earlier onset. $^{78}$

Dietz has highlighted the need for research into the factors that contribute to the development and persistence of overweight during adolescence in order to inform effective prevention. ${ }^{4}$ Ethnicity and socioeconomic status are consistently associated with risk of obesity, ${ }^{9-12}$ but few studies have systematically compared ethnic groups and socioeconomic status groups in relation to the development of adiposity in adolescence.

The health and behaviour in teenagers study (HABITS) is a five year longitudinal study, established in 1999, designed to investigate the development of cancer related risk factors, including smoking and obesity. This paper examines the developmental trajectory of weight and abdominal adiposity from age 11 to age 16 in relation to socioeconomic status, ethnicity, and sex.

\section{Methods}

We randomly selected 36 secondary schools in 13 boroughs in south London from all schools in the boroughs stratified by area and school type (inner London state $v$ outer London state $v$ independent; single sex $v$ mixed) to generate an ethnically and socioeconomically diverse sample. The study design is described in detail elsewhere. ${ }^{13}$ Data collection started in 1999 with students in year 7 (age 11-12) and continued annually to year 11 (age 15-16). All students registered in the relevant school year at the time of data collection were eligible to take part. We sent consent letters to parents, informing them of the study and giving them the option to exclude their child from participation. Students themselves were given individual written consent forms and informed of their right to withdraw from the study.

Trained researchers collected data, after visiting the schools and explaining the purpose of the study to the students. Students completed questionnaires covering demographic characteristics and a range of health behaviours, with assistance available from the researchers. We measured weights to the nearest $0.1 \mathrm{~kg}$ and heights to the nearest $0.1 \mathrm{~cm}$ by using TANITA scales and a Leicester freestanding stadiometer, with participants wearing light clothing without shoes. Waist measurements were taken under clothes, to the nearest $0.5 \mathrm{~cm}$ as described by McCarthy. ${ }^{14}$ Adult body mass index (BMI) criteria for overweight and obesity underestimate the extent of adverse adiposity in adolescents, so we established weight status by using the International Obesity 
Task Force criteria, ${ }^{15}$ which identify BMI values for each age associated with a predicted BMI of 25 or 30 at age $18 .{ }^{15}$ We calculated waist and BMI standard deviation (SD) scores by using the Excel growth macro for the British 1990 growth reference curves, which have a mean of 0 and a standard deviation of 1 at each age. ${ }^{1416}$

We collected ethnicity data by self report (white; black or mixed black; Asian or mixed Asian; other). The "other" ethnic group was heterogeneous and too small to subdivide $(\mathrm{n}=271)$, so we excluded it from our analyses. Students reported their postcodes, which we matched to enumeration districts to derive an area based measure of socioeconomic deprivation-the Townsend index..$^{17}$ This index is standardised across England and Wales, with zero representing the national average, negative values representing below average deprivation, and positive values representing above average deprivation.

We assessed pubertal status with items from the pubertal development scale. ${ }^{18}$ Further details are given in Simon et al. ${ }^{19}$

\section{Statistical analysis}

We examined the prevalence of overweight and obesity in the whole sample and by sex, socioeconomic status, and the three main ethnic subgroups. For these analyses, we weighted data according to the inverse sampling probability on the basis of school type. This gives results adjusted to the level expected if all schools in the London area had been randomly sampled. We used $\chi^{2}$ tests to assess differences in weighted rates between sexes, ethnic groups, and fifths of socioeconomic status.

We investigated variation between individual students in the rate of change of adiposity for absolute BMI and waist circumference, and for BMI and waist SD scores, by using a multilevel, linear mixed model analysis from MLwiN with student, school year, and school, at levels 1, 2, and 3. The inclusion of school as a top level random factor took account of within school clustering. The mixed models analysis fits a linear trend line for each student and does not need data from every visit, thereby maximising the use of available data. We examined the need for a non-linear component to the trend of adiposity, but it made a non-significant difference in the models for BMI and waist. A quadratic term improved the overall fit of the models for BMI SD and waist SD but none the less made only small differences to the coefficients of other explanatory variables. We therefore report the linear trend for all four models. We did not include pubertal status in the final models because evidence exists that puberty both is influenced by and influences adiposity, ${ }^{20}{ }^{21}$ and its inclusion might therefore represent "over-control." However, repeating the analyses with control for pubertal status did not change the pattern of results.

\section{Results}

In the first year, we recruited 4320 students, representing $84 \%$ of eligible students. Additional students $(n=1543)$ joined in later years, either because they had been absent from school on the day of data collection in earlier years or because they were new to the schools. Over the first four years, response rates among eligible students were consistently above $80 \%$. At each time point, between $1.5 \%$ and $5.5 \%$ of parents or students declined participation and between $10 \%$ and $15 \%$ of students were absent. In the final year, the participation rate dropped to $74 \%$ because two schools were unable to complete the data collection and more students were absent from classes through examination leave and out of school placements. Across all five years a total of 5863 students participated in the study: 36\% completed five years of data collection, $58 \%$ completed four years or more, $73 \%$
Table 1 Mean height, weight, body mass index (BMI), and waist circumference for participants present in year 7 , by sex and ethnicity. Values are mean $(\mathrm{SD})$

\begin{tabular}{lcccc} 
& White & $\begin{array}{c}\text { Black and mixed } \\
\text { black }\end{array}$ & $\begin{array}{c}\text { Asian and mixed } \\
\text { Asian }\end{array}$ & $\begin{array}{c}\text { Other/mixed } \\
\text { ethnic groups }\end{array}$ \\
\hline Girls & $\mathbf{( n = 1 0 1 0 )}$ & $\mathbf{( n = 4 5 4 )}$ & $\mathbf{( n = 1 7 5 )}$ & $\mathbf{( n = 8 7 )}$ \\
\hline Townsend index & $0.56(3.56)$ & $5.12(3.00)$ & $1.80(3.63)$ & $2.32(3.85)$ \\
\hline Age (years) & $11.8(0.3)$ & $11.8(0.3)$ & $11.8(0.3)$ & $11.9(0.3)$ \\
\hline Height $(\mathrm{cm})$ & $150.8(7.4)$ & $155.3(6.9)$ & $150.3(7.7)$ & $151.4(6.8)$ \\
\hline Weight $(\mathrm{kg})$ & $44.9(10.3)$ & $51.3(12.3)$ & $43.7(11.0)$ & $45.4(11.1)$ \\
\hline BMI & $19.6(3.5)$ & $21.1(4.2)$ & $19.2(3.6)$ & $19.7(4.3)$ \\
\hline BMI SD & $0.39(1.17)$ & $0.87(1.16)$ & $0.20(1.30)$ & $0.35(1.30)$ \\
\hline Waist $(\mathrm{cm})$ & $67.3(8.2)$ & $70.8(9.0)$ & $66.1(8.1)$ & $66.7(7.5)$ \\
\hline Waist SD & $1.09(1.09)$ & $1.56(1.01)$ & $0.92(1.15)$ & $1.01(1.03)$ \\
\hline Boys & $\mathbf{( n = 1 5 9 7 )}$ & $\mathbf{( n = 5 8 2 )}$ & $\mathbf{( n = 2 5 3 )}$ & $\mathbf{( n = 1 0 2 )}$ \\
\hline Townsend index & $0.37(3.25)$ & $3.88(3.12)$ & $1.97(3.35)$ & $3.35(3.11)$ \\
\hline Age $($ years $)$ & $11.8(0.4)$ & $11.8(0.4)$ & $11.9(0.4)$ & $11.8(0.4)$ \\
\hline Height $(\mathrm{cm})$ & $149.3(7.1)$ & $151.8(7.5)$ & $147.9(7.3)$ & $150.3(8.5)$ \\
\hline Weight $(\mathrm{kg})$ & $42.4(9.4)$ & $44.9(11.3)$ & $41.9(10.2)$ & $44.4(11.4)$ \\
\hline BMl & $18.9(3.1)$ & $19.3(3.9)$ & $19.0(3.4)$ & $19.4(3.5)$ \\
\hline BMI SD & $0.45(1.12)$ & $0.54(1.24)$ & $0.40(1.32)$ & $0.61(1.25)$ \\
\hline Waist $(\mathrm{cm})$ & $67.6(8.1)$ & $68.6(8.6)$ & $68.3(9.4)$ & $69.7(9.2)$ \\
\hline Waist SD & $0.78(0.95)$ & $0.90(0.95)$ & $0.79(1.14)$ & $1.03(1.00)$ \\
\hline
\end{tabular}

completed three years or more, and $88 \%$ completed at least two years.

We had weight, height, and waist measures for more than $97 \%$ of the students each year. The sample for the longitudinal analysis, after exclusion of students with missing data for ethnicity or socioeconomic status or in "other" ethnic groups, was 5320. Participants contributed an average of 3.7 out of 5 possible observations. Small-and mostly non-significant-trends existed towards larger waist and BMI measurements for students who were assessed on fewer of the annual occasions.

Table 1 shows results from year 7 (age 11-12). Black girls were significantly taller and heavier, and had a higher BMI, than white or Asian girls. Black boys were heaviest and tallest, and Asian boys were shortest. Waist circumferences were highest in black girls and boys (all $\mathrm{P}<0.001$ ).

\section{Prevalence of overweight and obesity}

The prevalence of overweight or obesity was high (table 2); between $16.9 \%$ and $19.3 \%$ of students were classified as overweight and an additional $5.5-6.9 \%$ as obese. More girls than boys were classified as overweight or obese in all years (all $\mathrm{P}<0.001)$. Rates of obesity increased over the five years in boys $(\mathrm{P}<0.001)$ and girls $(\mathrm{P}=0.009)$, but a corresponding decrease occurred in the rates of overweight. Overall, we found no change in the rates of overweight and obese combined, and therefore no reduction in the proportion classed as "healthy weight." Table 3 illustrates transitions in weight status by showing weight status at year 11 in relation to weight status at year 7 . The number of students who moved from overweight/obese to normal weight $(7.6 \%)$ was very similar to the number who moved from normal weight to overweight/obese $(7.0 \%)$.

Figure 1 shows time trends in prevalence of overweight and obesity by ethnicity, adjusted for socioeconomic status. In all five years of the study, black girls were significantly more likely to be overweight or obese than were white or Asian girls. White girls were slightly more likely to be obese or overweight than were Asian girls, with significant differences in three of the five years. The percentages of girls who were overweight or obese, averaged over the five years, after adjustment for socioeconomic status, were 28.0 for white, 38.2 for black, and 19.8 for Asian girls. Asian 
Table 2 Prevalence of overweight and obesity. Values are percentages (numbers)

\begin{tabular}{|c|c|c|c|c|c|}
\hline & Year 7 & Year 8 & Year 9 & Year 10 & Year 11 \\
\hline \multicolumn{6}{|l|}{ Whole sample } \\
\hline Healthy weight & 75.9 (3054) & 74.7 (3103) & 73.8 (2974) & 76.0 (3016) & 76.3 (2672) \\
\hline Overweight & 18.6 (750) & 19.3 (802) & $19.3(778)$ & 17.0 (676) & $16.9(592)$ \\
\hline Obese & $5.5(220)$ & 6.0 (248) & 6.9 (276) & 7.0 (277) & 6.8 (237) \\
\hline \multicolumn{6}{|l|}{ Girls } \\
\hline Healthy weight & 70.2 (1138) & 69.9 (1199) & 69.6 (1179) & 72.2 (1216) & 71.3 (1053) \\
\hline Overweight & 23.1 (374) & 23.0 (395) & $22.4(380)$ & 19.5 (329) & $20.4(301)$ \\
\hline Obese & 6.7 (109) & 7.1 (121) & 8.0 (135) & $8.3(140)$ & 8.3 (122) \\
\hline \multicolumn{6}{|l|}{ Boys } \\
\hline Healthy weight & 79.8 (1916) & 78.1 (1904) & 76.9 (1795) & 78.8 (1800) & 79.9 (1619) \\
\hline Overweight & 15.6 (376) & 16.7 (407) & 17.1 (398) & 15.2 (347) & $14.4(291)$ \\
\hline Obese & 4.6 (111) & $5.2(127)$ & 6.0 (141) & $6.0(137)$ & 5.7 (115) \\
\hline
\end{tabular}

boys had the highest rates for boys in all years, but ethnic differences were not significant on any occasion.

Figure 2 shows differences in rates of overweight and obesity by socioeconomic status, adjusted for ethnicity. Girls in the most deprived fifth had consistently higher rates of overweight or obesity (all $\mathrm{P}<0.001$ ). Averaged over the five years and after adjustment for ethnicity, $35.2 \%$ of the most deprived girls were overweight or obese compared with $27.8 \%$ of other girls. However, the trend across the other deprivation categories was inconsistent, with high levels of overweight and obesity in the least deprived girls in years 7 and 11. In boys, the most deprived

Table 3 Movement of pupils between weight categories. Values are numbers (percentages) from a total of 2654 cases with data from years 7 and 11

\begin{tabular}{lcccc}
\multirow{2}{*}{ Weight status in year 7 } & \multicolumn{5}{c}{ Weight status in year 11 } \\
\cline { 2 - 5 } & Normal weight & Overweight & Obese & Total \\
\hline Normal weight & $1842(69.4)$ & $192(7.2)$ & $10(0.4)$ & $2044(77.0)$ \\
\hline Overweight & $179(6.7)$ & $236(8.9)$ & $74(2.8)$ & $489(18.4)$ \\
\hline Obese & $8(0.3)$ & $29(1.1)$ & $84(3.2)$ & $121(4.6)$ \\
\hline Total & $2029(76.5)$ & $457(17.2)$ & $168(6.3)$ & 2654 \\
\hline
\end{tabular}

also had the highest rates of overweight or obesity, but results were not significant.

Adiposity trends over time-longitudinal change in adiposity Table 4 shows the absolute values of BMI and waist circumference by sex and ethnicity for each school year. We used mixed model analyses to estimate the independent effects of sex, ethnicity, and socioeconomic deprivation on the trends in BMI and waist circumference across the five time points, controlling for clustering by school (see table on bmj.com). BMI increased on average by 0.726 (SE 0.015) units per year from year 7 to year 11. Girls' mean BMI was higher than boys' by 1.042 (SE 0.112) units, but the rates of increase did not differ between boys and girls. We found a significant effect of socioeconomic status on BMI but no interactions between socioeconomic status and either sex or school year. Black students had BMI values 0.554 (SE 0.135) higher than white students. We found a significant sex by ethnic group interaction $(\mathrm{P}<0.001)$; black girls had an excess of 0.928 (SE 0.272) BMI units.

We did the same analyses for BMI standard deviation scores to examine the trajectory of relative adiposity compared with 1990. Boys and girls were initially 0.526 (SE 0.019) standard
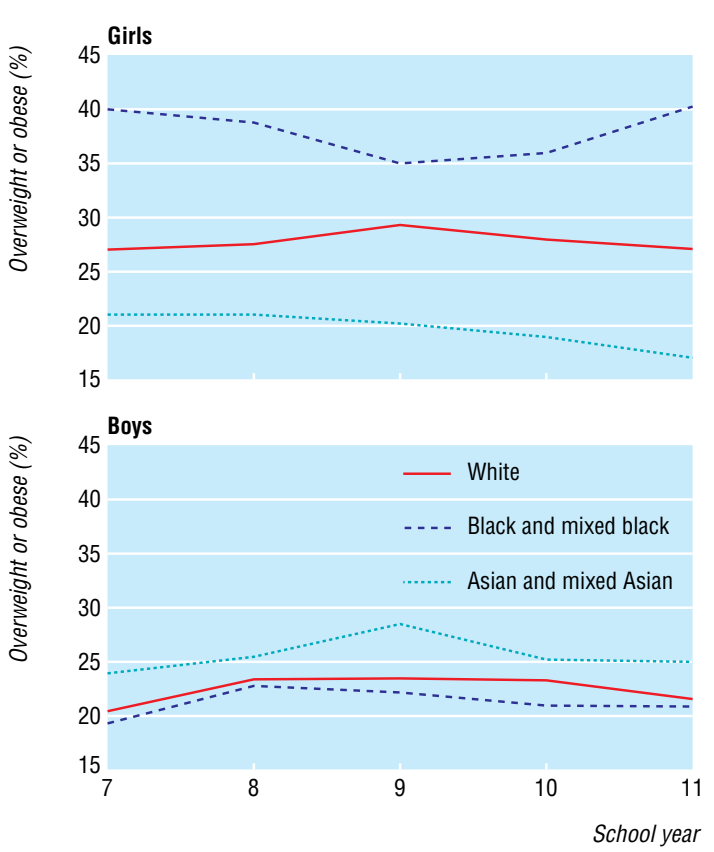

Fig 1 Rate of overweight by ethnicity ("other" ethnicity category excluded) for each year adjusted for socioeconomic status 
Table 4 Mean (SD) body mass index and waist circumference by sex, ethnicity, and year of study

\begin{tabular}{|c|c|c|c|c|c|}
\hline & Year 7 & Year 8 & Year 9 & Year 10 & Year 11 \\
\hline \multicolumn{6}{|l|}{ Body mass index } \\
\hline \multicolumn{6}{|l|}{ Girls: } \\
\hline White & $19.7(3.5)$ & $20.5(3.6)$ & $21.4(3.7)$ & $22.0(3.9)$ & $22.6(3.8)$ \\
\hline Black and mixed black & $21.2(4.1)$ & $22.0(4.1)$ & $22.7(4.3)$ & $23.4(4.5)$ & $24.1(4.6)$ \\
\hline Asian and mixed Asian & $19.3(3.5)$ & $19.7(3.2)$ & $20.5(3.4)$ & $21.1(3.6)$ & $21.4(3.3)$ \\
\hline \multicolumn{6}{|l|}{ Boys: } \\
\hline White & $18.9(3.1)$ & $19.7(3.3)$ & $20.5(3.3)$ & $21.2(3.5)$ & $21.8(3.5)$ \\
\hline Black and mixed black & $19.4(3.8)$ & $20.1(3.8)$ & $20.8(3.8)$ & $21.6(3.9)$ & $22.2(3.9)$ \\
\hline Asian and mixed Asian & $19.0(3.3)$ & $19.8(3.8)$ & $20.7(4.0)$ & $21.2(3.9)$ & $21.9(4.2)$ \\
\hline \multicolumn{6}{|l|}{ Waist circumference } \\
\hline \multicolumn{6}{|l|}{ Girls: } \\
\hline White & $67.1(7.3)$ & $68.8(7.4)$ & $71.2(7.8)$ & $73.1(8.2)$ & $74.8(8.4)$ \\
\hline Black and mixed black & $70.6(8.1)$ & $72.1(8.1)$ & $74.1(8.6)$ & $75.7(9.1)$ & $77.3(8.5)$ \\
\hline Asian and mixed Asian & $65.8(6.9)$ & $67.2(6.8)$ & $69.0(7.1)$ & $70.8(7.2)$ & $71.6(9.9)$ \\
\hline \multicolumn{6}{|l|}{ Boys: } \\
\hline White & $67.4(7.4)$ & $70.2(7.8)$ & $73.3(8.0)$ & $76.3(8.3)$ & $78.8(8.4)$ \\
\hline Black and mixed black & $68.4(7.8)$ & $70.8(7.8)$ & $73.4(7.9)$ & $76.0(8.4)$ & $78.5(8.5)$ \\
\hline Asian and mixed Asian & $68.1(8.5)$ & $70.8(8.8)$ & $74.0(9.3)$ & $76.5(9.1)$ & $79.1(9.9)$ \\
\hline
\end{tabular}

deviations above the 1990 norms, with a slight upward trend over time of 0.024 units per annum (SE 0.004). Black students' BMI standard deviation scores were 0.148 (SE 0.042) higher than those of white students, and Asian students' scores were 0.151 (SE 0.051) lower. BMI standard deviation scores were higher in the more socioeconomically deprived groups $(\mathrm{P}=0.007)$, but interactions between socioeconomic status and school year were not statistically significant.

\section{Trends in abdominal adiposity}

Waist circumferences increased on average by 2.31 (SE 0.09) $\mathrm{cm}$ /year from year 7 to year 11; the increase in boys was 0.992 (SE 0.082$) \mathrm{cm}$ greater than that in girls. Waist circumferences were significantly higher in lower socioeconomic status groups $(\mathrm{P}<0.007)$, but we found no significant interactions by sex or school year. We found a significant sex by ethnic group interaction $(\mathrm{P}<0.001)$; black girls had waist circumferences 2.138 (SE $0.638) \mathrm{cm}$ larger than white girls, and Asians had the smallest waists $(\mathrm{P}<0.001)$, but little difference existed between ethnic groups among boys. However, the mean annual rate of increase was $0.266 \mathrm{~cm}$ (SE 0.077) lower in black students than in white students.

Students entered the study with waist standard deviation values markedly higher than the 1990 reference level-boys by 0.798 (SE 0.019); girls by 1.15 (SE 0.03). Over the next four years, girls deviated even further from these levels to reach 1.44 (SE 0.030) standard deviation units above their 1990 norms by age 15-16, whereas boys reached 0.926 (SE 0.022). The school year by sex interaction was statistically significant $(\mathrm{P}<0.001)$. Black students' waist standard deviation scores were higher than those of white students by 0.110 (SE 0.037) units, but the annual rate of increase was 0.034 (SE 0.009) less than that of white students. This ethnicity by school year interaction was statistically significant $(\mathrm{P}<0.001)$. We found a trend towards higher waist standard deviation scores with increased deprivation $(\mathrm{P}=0.016)$.
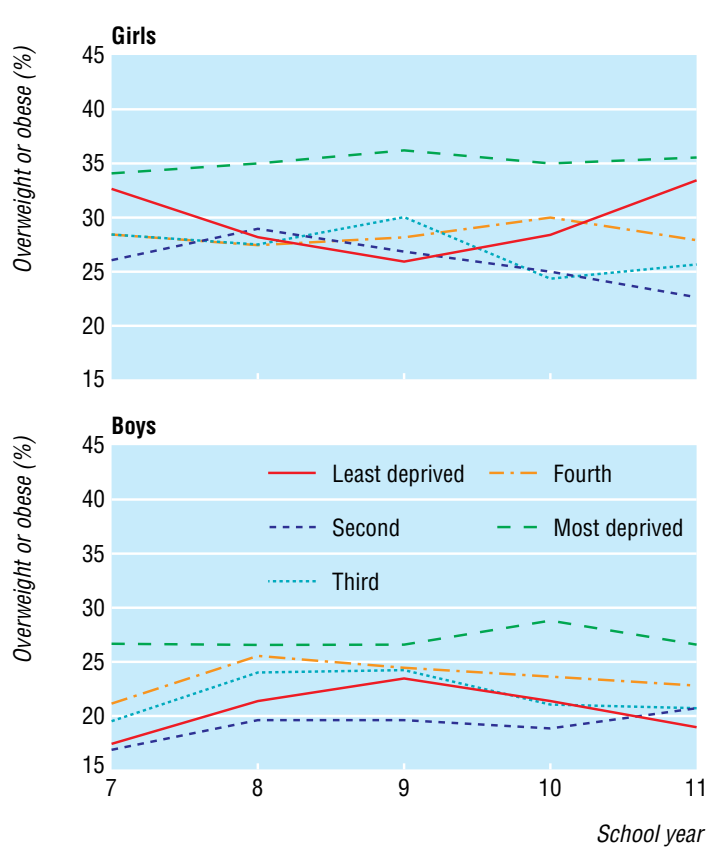

Fig 2 Rate of overweight by socioeconomic status for each year adjusted for ethnicity ("other" ethnicity category excluded) 
Table 5 Correlations for body mass index scores across five years of study (all results significant to $\mathrm{P}<0.001$ )

\begin{tabular}{lcccc} 
Body mass index & Year 7 & Year 8 & Year 9 & Year 10 \\
\hline Year 8 & 0.95 & - & - & - \\
\hline Year 9 & 0.91 & 0.94 & - & - \\
\hline Year 10 & 0.87 & 0.90 & 0.94 & - \\
\hline Year 11 & 0.82 & 0.86 & 0.90 & 0.95 \\
\hline
\end{tabular}

\section{Tracking of adiposity}

Correlations between BMI scores at different time points give an indication of "tracking." The size of the correlations was similar in girls and boys, so table 5 shows correlations for BMI scores across the five assessment points for both sexes combined. Year to year correlations were extremely high, running at 0.94 for a one year interval between measurements, and reducing to 0.90 , 0.86 , and 0.82 for two, three, and four year intervals. The pattern for tracking of waist circumference was similar, with correlations going from 0.86 for a one year measurement interval to 0.70 for a four year interval (table 6).

\section{Discussion}

\section{Development of adiposity}

Adolescence is often highlighted as a critical period for the development of persistent obesity. ${ }^{4}$ Both socioeconomic status and ethnicity are implicated as risk factors in the emergence of adolescent obesity, ${ }^{10}$ although few longitudinal studies have been done. Our cohort showed the high rates of overweight and obesity at entry that we have come to expect in recent years. Rates were higher for students living in lower socioeconomic status neighbourhoods and for girls from black ethnic groups. Over this four year period, obesity rates went up by one to two percentage points, but rates of overweight declined by the same amount, so the proportion of students with body sizes in the healthy weight range was unchanged. This pattern is more consistent with increasing adiposity in a vulnerable subgroup than with an overall effect on adiposity; an effect that has also been noted in France, Belgium, and the United States. ${ }^{102} 23$

Adiposity tracked strongly over time-BMI correlations from year to year were greater than 0.9 at one and two year intervals and above 0.8 for three and four year intervals. This indicates that the children who are fatter than average at age 11 are likely still to be fatter at age 15. Transitions from overweight or obese to normal weight showed that if excess adiposity is present early in adolescence (taken here as age 11), it is highly likely to persist. In our sample, very few students who were obese in year 7 later changed to normal weight status. Obesity in early adolescence is a clear indication of persistent obesity.

The finding that the proportion of adolescents in the healthy weight range did not decrease over time suggests that the major development of early adiposity is fully established by age 11 . Thus the high risk period for onset of persistent obesity may be in the pre-adolescent years, which has important implications for targeting preventive efforts.

Table 6 Correlations for waist circumference scores across five years of study (all results significant to $\mathrm{P}<0.001$ )

\begin{tabular}{lcccc} 
Waist circumference & Year $\mathbf{7}$ & Year $\mathbf{8}$ & Year 9 & Year 10 \\
\hline Year 8 & 0.86 & & & \\
\hline Year 9 & 0.76 & 0.83 & & \\
\hline Year 10 & 0.76 & 0.81 & 0.81 & \\
\hline Year 11 & 0.70 & 0.76 & 0.76 & 0.83 \\
\hline
\end{tabular}

\section{Time trends in adiposity}

On the basis of BMI standard deviation scores, which index BMI relative to 1990 age and sex norms, a small but significant increase in relative adiposity seemed to occur over time as the cohort matured. These results suggest that the modern "obesogenic" environment in Britain is steadily increasing body fat stores in adolescents.

The levels of adiposity identified here can be compared with national statistics by using data from the health survey for England for 1997 and 2002, both of which were enriched for children and young people. Health survey data are predominantly from white respondents, so are best compared with data from our white students. Mean BMI for 12 year olds in the 1997 survey was 18.5 for boys and 19.2 for girls. By 2002, mean BMI for 12 year olds had increased to 19.4 for boys and 20.0 for girls, an increase of around $0.8 \mathrm{BMI}$ points. ${ }^{24}$ Our data for white students in 1999 were around 0.35 BMI points higher than the 1997 values, consistent with the national population trends.

National data show dramatic increases in adolescents' waist sizes since $1990,{ }^{25}$ and our results suggest that waists have become even larger, especially among girls from black ethnic groups. The high level of tracking for waist circumference indicates that risks for metabolic syndrome are developing very early in life.

\section{Socioeconomic differences in adiposity}

We found strong evidence for ethnic differences-black girls had almost double the prevalence of overweight and obesity of white girls, an effect that persisted over all five years of the study. The ethnic difference was restricted to girls, a phenomenon that has been noted in other studies, and persists into adult life, but is poorly understood. Mechanisms could include the earlier development of adiposity in black girls, ${ }^{20}$ which is supported by the flatter slope for the trends in waist measurements in black students.

Differences with socioeconomic status were less clear cut. Using residential area as a marker of socioeconomic status, students in the lowest fifth had higher rates of overweight and obesity, and this pattern was maintained over the five years of assessment and seen in both sexes. No further divergence occurred, indicating that differences with socioeconomic status are established before age 11. However, differences were not systematically graded across levels of socioeconomic status, and rates of overweight and obesity were also high in the least deprived girls in years 7 and 11. Results from other samples of adolescents have been mixed; some studies have found no differences, ${ }^{9}$ whereas others have found differences but not always graded across levels of socioeconomic status. ${ }^{11}{ }^{12}$ More work is needed to understand when in the developmental process differences in adiposity by socioeconomic status emerge.

\section{Limitations}

Several factors limit generalisation of these results. The sample is restricted to an urban British setting. However, it has the advantage of a large sample size and strong representation from ethnic minorities. As with most longitudinal studies, retention of participants is a problem, and a degree of participation bias occurred, whereby students seen on fewer occasions had slightly larger waists and BMIs. This means that the prevalence of obesity and overweight may be very slightly underestimated. The broad classification of ethnicity means that conclusions cannot be drawn about variation within ethnic subgroups. The higher rates of adiposity in the group that we termed "black and mixed black" could be specific to one ethnic subgroup, but larger samples would be needed to identify differences. 


\section{Research}

\section{Conclusions}

The results of this study give cause for concern. Levels of obesity are high and rising, and the socioeconomic and ethnic differences seen suggest that obesity will contribute to increasing health inequalities as this cohort matures. Central adiposity seems to be increasing particularly rapidly. The strong tracking of both BMI and waist circumference from age 11, and the rarity of transitions from obese to normal weight, indicates that any notion of "puppy fat" that disappears on maturation must be abandoned; children who are obese when they enter secondary school will very likely leave it obese. The results highlight the need to examine the trajectory of adiposity earlier in childhood, because the high risk period may be getting earlier. Surveillance of the anthropometric status of young people in Britain is of critical importance for monitoring the progression of the obesity problem and evaluating the success of public health interventions.

We gratefully acknowledge the participation of the 36 schools and 5863 students and the work of all those involved in collecting the data.

Contributors: All authors participated in the conception, analysis, and interpretation of the study. JW and NHB wrote the manuscript, and JW, $\mathrm{DRB}, \mathrm{TJC}$, and $\mathrm{MJJ}$ were involved in revising the original manuscript. JW is the guarantor.

Funding: This research was supported by Cancer Research UK, which had no involvement in the study itself or its interpretation.

Competing interests: None declared.

Ethical approval: University College London/University College London Hospital medical ethics committee.

\section{What is already known on this topic}

Adolescence is assumed to be a critical period for the development of obesity, but no UK data on developmental trends in adolescence exist

Adults show strong demographic patterning of obesity (higher prevalence in lower socioeconomic groups and black women), but whether this emerges in adolescence is unknown

Abdominal adiposity, indexed by waist circumference, rose dramatically in children and adolescents in the 1990s and may be continuing to rise

\section{What this study adds}

Few incident cases of overweight emerged during adolescence, suggesting that pre-adolescence may be the higher risk period

Obesity was most prevalent in lower socioeconomic groups; no evidence exists for increasing socioeconomic inequalities over the adolescent years

Young black women have strikingly high rates of obesity, which are not matched in young black men
1 Lobstein TJ, James WPT, Cole TJ. Increasing levels of excess weight among children in England. Int J Obes 2003;27:1136-8.

2 Bundred P, Kitchiner D, Buchan I. Prevalence of overweight and obese children between 1989 and 1998: population based series of cross sectional studies. BMJ 2001;322:326-8.

3 Ogden CL, Flegal KM, Carroll MD, Johnson CL. Prevalence and trends in overweigh among US children and adolescents, 1999-2000. JAMA 2002;288:1728-32.

Dietz WH. Overweight in childhood and adolescence. N EnglJ Med 9004:350:855-7.

5 Guo SS, Chumlea WC. Tracking of body mass index in children in relation to overweight in adulthood. Am J Clin Nutr 1999:70:145-8S

6 Freedman DS, Khan LK, Serdula MK, Dietz WH, Srinivasan SR, Berenson GS. The relation of childhood BMI to adult adiposity: the Bogalusa heart study. Pediatrics 2005; $115: 22-7$.

7 Vanhala M, Vanhala P, Kumpusalo E, Halonen P, Takala J. Relation between obesity from childhood to adulthood and the metabolic syndrome: population based study. BMJ 1998;317:319.

8 Wardle J, Waller J, Fox E. Age of onset and body dissatisfaction in obesity. Addict Behav 2002;27:561-73.

9 Saxena S, Ambler G, Cole TJ, Majeed A. Ethnic group differences in overweight and obese children and young people in England: cross sectional survey. Arch Dis Child 2004;89:30-6.

10 Parsons TJ, Power C, Logan S, Summerbell CD. Childhood predictors of adult obesity: a systematic review. Int J Obes Relat Metab Disord 1999;23(suppl 8):S1-107.

11 Romon M, Duhamel A, Collinet N, Weill J. Influence of social class on time trends in BMI distribution in 5-year-old French children from 1989 to 1999. Int J Obes 2005;29:54-9.

12 Wang Y. Cross-national comparison of childhood obesity: the epidemic and the relationship between obesity and socioeconomic status. Int J Epidemiol 2001:30:1129-

13 Wardle J, Jarvis MJ, Steggles N, Sutton S, Williamson S, Farrimond H, et al. Socioeconomic disparities in cancer-risk behaviors in adolescence: baseline results from the health and behaviour in teenagers study (HABITS). Prev Med 2003;36:721-30.

14 McCarthy HD, Jarrett KV, Crawley HF. The development of waist circumference percentiles in British children aged 5.0-16.9 y. Eur J Clin Nutr 2001;55:902-7.

15 Cole TJ, Bellizzi MC, Flegal KM, Dietz WH. Establishing a standard definition for child overweight and obesity worldwide: international survey. BMJ 2000;320:1240-3.

16 Cole TJ, Freeman JV, Preece MA. Body mass index reference curves for the UK, 1990 Arch Dis Child 1995;73:25-9.

17 Townsend P, Phillimore P, Beattie A. Health and deprivation: inequalities and the North London: Croom Helm, 1998.

18 Petersen AC, Crockett L, Richards M, Boxer A. A self-report measure of pubertal status-reliability, validity, and initial norms. J Youth Adolesc 1988;17:117-33.

19 Simon AE, Wardle J, Jarvis MJ, Steggles N, Cartwright M. Examining the relationship between pubertal stage, adolescent health behaviours and stress. Psychol Med 2003;33:1369-79.

20 Kaplowitz PB, Slora EJ, Wasserman RC, Pedlow SE, Herman-Giddens ME. Earlier onset of puberty in girls: relation to increased body mass index and race. Pediatrics 2001;108:347-53.

21 Demerath EW, Li J, Sun SS, Chumlea WC, Remsberg KE, Czerwinski SA, et al. Fifty-year trends in serial body mass index during adolescence in girls: the Fels longitudinal study. Am J Clin Nutr 2004;80:441-6.

22 Flegal KM, Troiano RP. Changes in the distribution of body mass index of adults and children in the US population. Int J Obes 2000;24:807-18.

23 Hulens M, Beunen G, Claessens AL, Lefevre J, Thomis M, Philippaerts R, et al. Trends in BMI among Belgian children, adolescents and adults from 1969 to 1996. Int J Obes 2001;25:395-9.

24 Department of Health. Health survey for England. 1994-2004. www.dh.gov.uk/ PublicationsAndStatistics/PublishedSurvey/HealthSurveyForEngland/fs/en (accessed 12 April 2006).

25 McCarthy HD, Ellis SM, Cole TJ. Central overweight and obesity in British youth aged 11-16 years: cross sectional surveys of waist circumference. BMJ 2003;326:624.

(Accepted 7 March 2006)

doi 10.1136/bmj.38807.594792.AE

Cancer Research UK Health Behaviour Unit, Department of Epidemiology and Public Health, University College London, London WC1E 6BT

Jane Wardle professor of clinical psychology

Naomi Henning Brodersen research fellow

Martin J Jarvis emeritus professor of health psychology

David R Boniface statistician

Department of Epidemiology and Public Health, Institute of Child Health, London WC1N 1EH

Tim J Cole professor of medical statistics

Correspondence to:J Wardle j.wardle@ucl.ac.uk 